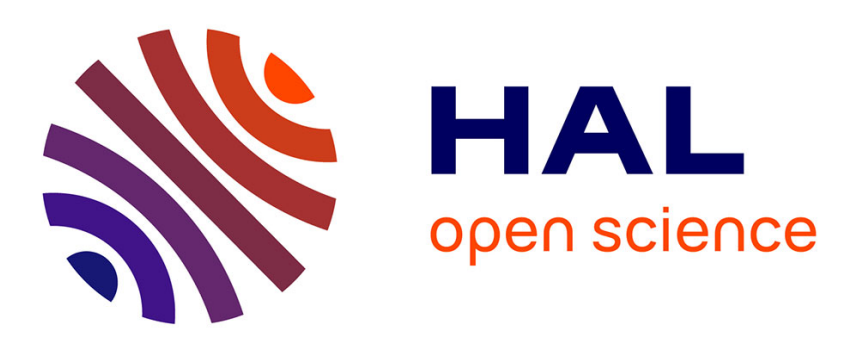

\title{
Nanostructural and nanochemical investigation of luminescent photoelectrochemically etched porous n-type silicon
}

\author{
A. Albu-Yaron, S. Bastide, D. Bouchet, N. Brun, C. Colliex, C. Lévy-Clément
}

\section{- To cite this version:}

A. Albu-Yaron, S. Bastide, D. Bouchet, N. Brun, C. Colliex, et al.. Nanostructural and nanochemical investigation of luminescent photoelectrochemically etched porous n-type silicon. Journal de Physique I, 1994, 4 (8), pp.1181-1197. 10.1051/jp1:1994248 • jpa-00246978

\section{HAL Id: jpa-00246978 https://hal.science/jpa-00246978}

Submitted on 1 Jan 1994

HAL is a multi-disciplinary open access archive for the deposit and dissemination of scientific research documents, whether they are published or not. The documents may come from teaching and research institutions in France or abroad, or from public or private research centers.
L'archive ouverte pluridisciplinaire HAL, est destinée au dépôt et à la diffusion de documents scientifiques de niveau recherche, publiés ou non, émanant des établissements d'enseignement et de recherche français ou étrangers, des laboratoires publics ou privés. 
Classification

Physics Abstracts

$60.00-61.16 \mathrm{~B}-78.55$

\title{
Nanostructural and nanochemical investigation of luminescent photoelectrochemically etched porous n-type silicon
}

\author{
A. Albu-Yaron $\left({ }^{1}, *\right)$, S. Bastide $\left({ }^{1}\right)$, D. Bouchet $\left({ }^{2}\right)$, N. Brun $\left({ }^{2}\right)$, C. Colliex $\left({ }^{2}\right)$ \\ and C. Lévy-Clément $\left({ }^{1}\right)$ \\ (1) Laboratoire de Physique des Solıdes de Bellevue (**) 1 place Aristıde Briand, 92195 \\ Meudon, France \\ (2) Laboratorre de Physique des Solıdes $\left({ }^{* * *}\right)$, Bât. 510, Université Paris-Sud, 91405 Orsay, \\ France
}

(Recelved 2 February 1994, accepted in final form 2 May 1994)

\begin{abstract}
Porous slicon obtained on n-type sllicon by photoelectrochemical etching in HF, is formed of a macroporous silicon layer beneath a nanoporous silicon layer. Microstructural investigations and chemical analysis at the atomic level of the nanoporous silicon film (obtained from a highly doped (111) oriented Si substrate) have been done by high resolution transmission electron microscopy (HRTEM) and electron energy loss spectroscopy (EELS) usıng a scanning transmission electron microscope (STEM). We have found that the nanoporous Si consists of a regular Si macroarray with triangular geometry. Nanometer-size tangled wires are contaned within and attached to the macroarray. HRTEM images clearly demonstrate the existence of quantum-sized Si wires made of a crystalline core covered with an amorphous layer. Electron energy loss spectra (EELS) have been recorded for different positions of the incident probe across the quantum-sized $\mathrm{Si}$ wires. The results obtained in the low-loss region and at the $\mathrm{Si} \mathrm{L}_{23}$ edge have been compared with those recorded on reference specimens $\left(\mathrm{Si} / \mathrm{SiO}_{2}\right.$ interface and hydrogenated $\mathrm{Si}$ sample). Although they do not exclude the presence of one or a few monolayers of foreign species, of hydrogen in particular, on the outer surface, our results generally support the quantumconfinement model to interpret the observed photoluminescence in nanoporous Si.
\end{abstract}

\section{Introduction.}

The remarkable nature of the conversion, by electrochemical or photoelectrochemical anodic dissolution, of a monocrystalline silıcon surface into a porous layer, that emits visible light at room temperature well above the $1 \mathrm{leV}$ energy of the indirect band gap of silicon [1] has

(*) Permanent address: ARO, the Volcan Centre, POB 6, Bet Dagan 50250, Israel.

(**) CNRS UPR 1332.

(***) Associé au CNRS, URA 002. 
stimulated many studies for both theoretical and experimental reasons [2]. These studies are motivated by a fundamental interest in the involved physical properties (morphology, structure formation, evolution, size quantization and luminescence) and their potentıal application to the fabrication of light emitting silicon devices integrated with the well developed silicon technology [3, 4]. However, this extensive experimental and theoretical work has resulted in scattered interpretations and controversial debates that have not yet provided an unambiguous description of the exact mechanism underlying this effect [2].

Under the generic name of porous silicon there are different and complex materials whose properties - structural, optical, electrical, surface and mechanical - critically depend on many parameters [5-7], such as Si conductivity type, resistivity, crystallographic orientation, current density electrolyte nominal concentration, $\mathrm{pH}$ and light intensity (for $\mathrm{n}-\mathrm{Si}$ ). A porous silicon surface layer is in general formed on p-type (lightly $\left(\mathrm{p}^{-}\right)$and highly $\left(\mathrm{p}^{+}\right)$doped) and $\mathrm{n}^{+}$ type $\mathrm{Si}$ by electrochemical oxidation under anodic polarization of silicon in aqueous $\mathrm{HF}$ electrolyte (electrochemical etching : «EC-etching »). For n-type Si, illumination is necessary (photoelectrochemical etching: «PEC-etching»). Most published work with anodized Si concerns the p-type material while very few studies of the nature of the surface Si layer on $\mathbf{n}$ type $\mathrm{Si}$ have been reported until now.

In previous papers we have reported for the first time details of the morphology and surface chemistry of photoelectrochemically etched (PEC-etched) n-type Si in HF and shown that it leads to the formation of a surface with unique features, different from those obtained by the EC-etching process [7-11]. Two different layers of porous silicon, near the surface of the ntype Si electrode were simultaneously formed. The top surface layer is highly resistive. It can easily be dissolved by $\mathrm{KOH}$. For (100) oriented Si, this layer shows X-ray and electron diffraction patterns similar to the parent silicon [9]. Room temperature photoluminescence originated in this layer and the luminescence spectrum was shown to shift with change of the doping density of the silicon [12]. Transmission electron microscopy (TEM) studies have revealed nanometer sized tangled Si wires in the quantum size range, contained within and attached to a regular geometric Si macroarray. They have also shown subtle variations in morphology between top surface porous layers obtained with various doping levels, which could explain the blue shift in the spectrum of the low doped specimens - thinner and more rigid irregular wires as compared to the highly doped specimens - This top surface layer is named nanoporous Si layer in opposition to the macroporous Si layer formed underneath in which macropores of micron size diameter are present [10]. A detailed study of the morphology of the macroporous Si layer reported elsewhere [10] has demonstrated that the shape of the macropores strongly depends on the doping density and crystallographic orientation of the parent silicon. Interestingly, no photoluminescence originated from this layer [12].

The luminescent properties, uncharacteristic of bulk $\mathrm{Si}$ material but specific to the artificially fabricated porous surface structures, are intimately related to the microstructure. The internal structural features which can govern the optical emission properties are the grain size in the quantum size range, the coexistence of various phases, the presence of impurities, composition gradient of varying stoichiometry [1, 13-19]. To assist in further understanding of the origin of the visible room temperature luminescence, the determination of the real microstructure and microchemical analysis of the nanometer sized tangle wires forming the ntype porous Si is necessary. In the present work High Resolution Transmission Electron Microscopy (HRTEM) has been attempted for direct imaging of nanometer size features at atomic resolution, together with Electron Energy Loss Spectrometry (EELS) which offers a higher spatial resolution compared to other methods used for chemical analysis. In this paper we have investigated directly the local surface morphology, structure and chemical composi- 
tion of the nanometer size silicon layer formed in a conventional anodization process by PECetching of n-type $\operatorname{Si}(111)$ oriented with a phosphorus doping density of $n_{\mathrm{d}}=2 \times 10^{18} \mathrm{~cm}^{-3}$. A method of obtaining fairly large areas of plan-view specimens has been developed and used throughout these studies. We have also resorted to ultramicrotomy to prepare cross-section specimens of good quality in the form required for cross sectional HRTEM and high spatial resolution EELS investıgations.

\section{Experimental.}

2.1 POROUS FILM PREPARATION. - The anodization was performed in a three electrode perspex cell, under selected potentıostatic regimes, with the Si wafer as the anode, a Pt wire as the cathode and a calomel electrode (SCE) as the reference electrode connected to the cell $i \mathrm{la}$ a salt bridge. The geometry of the cell allows a $0.4 \mathrm{~cm}^{2}$ circular shaped area to be horizontally displayed to the electrolyte for direct optical exposure.

Before mountıng, samples were surface treated in boiling methanol for $5 \mathrm{~min}$, in a mixture of $\mathrm{HNO}_{3}(69 \%): \mathrm{CH}_{3} \mathrm{COOH}(95 \%): \mathrm{HF}(48 \%)=16: 3: 1$ (by volume) for $5 \mathrm{~min}$ and subsequently well rinsed in de-ionized water. Ohmic contact was provided by painting with a Ga-In eutectic the backside of the samples to be exposed to the electrolyte. The electrolyte was $2.8 \mathrm{M}$ aqueous hydrofluoric acıd (5\%) with a few drops of a wettıng agent (triton X-100). It was stirred slightly during the experiments using a low stream of Ar to remove hydrogen bubbles from the sample surface.

PEC-etching was carried out at $0.1 \mathrm{~V}$ versus the SCE (calomel electrode), under an 1rradiance (white light collimated beam from a tungsten-halogen lamp) of $50 \mathrm{~mW} . \mathrm{cm}^{-2}$, untıl a predetermined charge of $10 \mathrm{C} . \mathrm{cm}^{-2}$ was passed through the sample. These conditions were chosen in order to work in the porous Si formation range, where electropolishing is avoided.

The samples mounted in the electrochemical cell were connected to a potentiostat (Wenking model ST88), a voltage integrator (Wenking model EV 180) and a voltage scan generator (Wenking model VS 672) for supply and measurement of the charge exchanged during the anodization. All experiments were conducted at room temperature.

The supply of holes at the semiconductor surface, required for anodization, was assisted by illumination. Samples were illuminated with white light by a collimated beam from a $300 \mathrm{~W}$, $20 \mathrm{~V}$ tungstem lamp (Sylvania) at a distance of $20 \mathrm{~cm}$.

After anodization, an electropolishing step consisting of anodization at anodic overpotentials in diluted ( $5 \% \mathrm{HF}$ ) aqueous electrolyte and under illumination was performed to lift off the films. The detached porous silicon layers (PSL) were both rınsed and stored in methanol (to avold damages due to drying of the material in air) for structural and morphological studies by transmission electron microscopy (TEM).

The Si wafers after anodization were rinsed in de-jonızed water, dried and their surface morphology evaluated by SEM.

2.2 Porous Film Characterization. - Two sets of specimens were prepared for observation by TEM.

a) Plan-v'sew' specimens. - The detached platelets of PSL, floating on the methanol, were caught on $3 \mathrm{~mm}$ diameter, 200 mesh copper grids, and examıned directly. However occasionally the PSL platelets were reduced in thickness by dipping for a few seconds in diluted $\mathrm{KOH}$ at room temperature.

b) Cross-sectional specimens. - Microtomy was used in order to avold the potentially harmful processes to the PSL films involved in conventional preparation techniques such as mechanical grinding or con-beam thinning. A thorough discussion of this technique has been presented in a prevıous paper [20]. Briefly, discrete PSL pieces of size approximately 
$1.5 \mathrm{~mm} \times 2 \mathrm{~mm}$ were embedded in an epoxy resin, with subsequent curing of the resin at 70$80^{\circ} \mathrm{C}$ for 18 hours following a procedure developed by us. The resin block with the embedded PSL strip was directly clamped into the specimen holder of the microtome and roughly cut to a standard pyramidal tip. Within the tip, the layer direction was oriented at various angles to the cuttıng direction of the knife. Occasionally, cutting was at an angle of $15^{\circ} \pm 10^{\circ}$ to ensure that directional knife artifacts were not aligned with the layer structure and could easily be distinguished.

Cutting was performed usıng an ultramicrotome (Microtome Reichert-Jung) with a diamond knife (diatome) $1.8 \mathrm{~mm}$, mounted at the edge of a water «boat $»$ at a knife angle of about $6^{\circ}$. A cutting speed of $2.0 \mathrm{~mm} \mathrm{~s}^{-1}$ and an advance of $50-70 \mathrm{~nm}$ per cutting cycle were found suitable in this case. The sections were collected on the surface of the water contained in the boated knife and immediately picked up on 200 mesh carbon film loaded copper grids by simply touching the sections.

Typical sections varied between 45 and $65-70 \mathrm{~nm}$ in thickness. 5-6 sections were collected on each grid and among them enough transparent damage-free material was found for TEM study.

Photoluminescence at room temperature was measured with a conventional setup equipped with a HUET M65 monochromator. The excitation source was the $488 \mathrm{~nm}$ line of a $20 \mathrm{~mW}$ argon-1on laser (Ion Laser Technology). The emitted light was captured by a photomultiplier.

SEM observation was performed on plan-view specimens previously coated with a thin layer of gold using a JEOL-JSM 840 scanning electron microscope operated at $10 \mathrm{kV}$.

Conventional medium resolution TEM images and electron diffraction patterns were obtained using a JEOL-100 CXII at $100 \mathrm{kV}$. High resolution transmission electron microscopy (HRTEM), both in plan-view and cross-section. was carried out on a AKASHI EM-002B, $200 \mathrm{kV}$, fitted with a high resolution $\left(C_{3}=0.4 \mathrm{~mm}\right.$ with point resolution of $0.18 \mathrm{~nm}$ at $200 \mathrm{kV})$ pole-prece and a side-entry double tilt goniometer stage $\left( \pm 10^{\circ}\right)$. A slow scan camera (SSC) using a charge-coupled device (Gatan Ltd) linked with a Macintosh Quadra 950 was used for HRTEM image recording, on-lıne processing and analysis, as the SSC image digitızer can be used to Fourier transform the HR images for computer-automated diffractogram analysis.

Energy loss spectroscopy was performed on a dedicated VG STEM instrument fitted with a field emission source and a Gatan 666 parallel EELS spectrometer. In order to investigate in detail the spatial dependence of EELS features we have used the recently developed spectrum-lıne or -image mode [21]. It consists of acquiring sequences of spectra while the incident probe is scanned under digital control over the specimen surface, for instance across a selected fiber in the specimen. A minimum probe size of the order of $0.5-0.6 \mathrm{~nm}$ can be obtained when using the illumination parameters under optimal conditions [22]. The pixel increment can be varied at will and a value of $0.3-0.7 \mathrm{~nm}$ has generally been used in order to be close to optimum sampling conditions. This method provides a unique opportunity for investigating the EELS spectrum (with a typical $0.6 \mathrm{eV}$ energy resolution) as a function of position on the specimen. Two distinct energy loss domains have been studied extensively : the $0-30 \mathrm{eV}$ range covering the individual and collective excitation of valence electrons and the $90-150 \mathrm{eV}$ corresponding to the excitation of silicon $2 p$ electrons. The EELS operating parameters (angle of collection, spectrum acquisıtion time, energy dispersion of the diode array.. ) have been adjusted in order to achieve optimum signal acquisition conditions for each case.

\section{Results.}

3.1 PhotoluminesCenCE. - Figure 1 shows the room temperature photoluminescence spectrum of the silicon immediately after PEC-etching. Prior to PEC-etching no photolumı- 


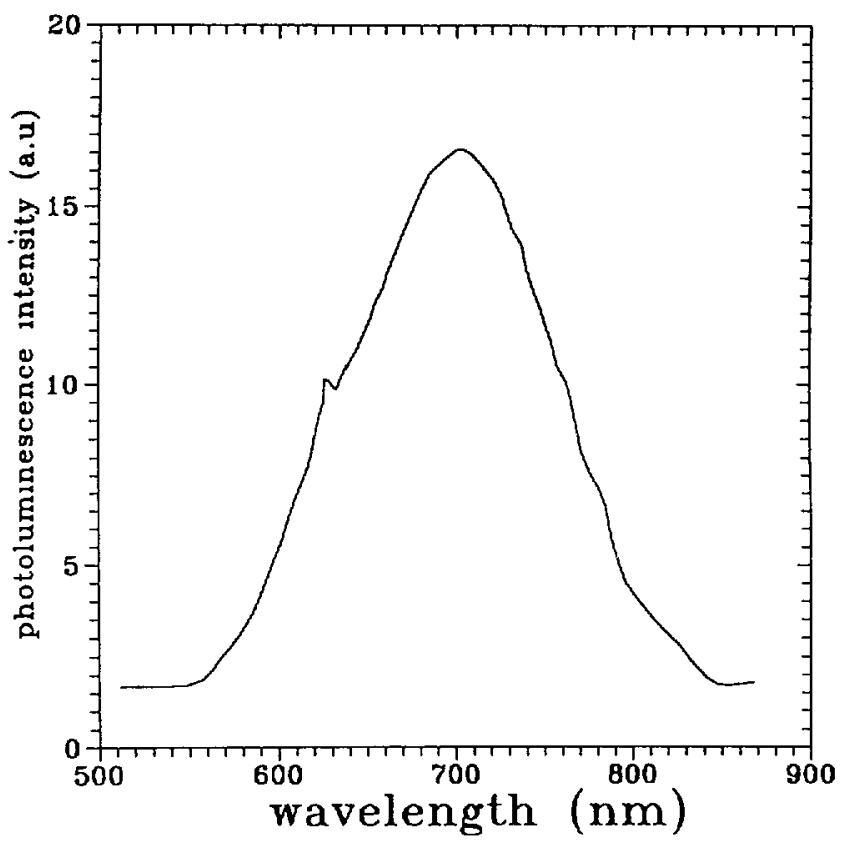

Fig. 1. - Photoluminescence at room temperature of PEC-etched Si $\left(n_{\mathrm{d}}=2 \times 10^{18} \mathrm{~cm}^{-3}\right.$, $Q=10 \mathrm{C} \mathrm{cm}^{-2}$ )

nescence could be observed in this spectral range. The maxımum of the spectrum is situated at about $700 \mathrm{~nm}$. After dissolution of the nanoporous layer in $2 \mathrm{M} \mathrm{KOH}$, no photoluminescence signal was detected from the macroporous Si layer.

3.2 MORPHOLOGY AND MICROSTRUCTURE. - SEM plan-view micrographs of the outer surface (Fig. 2a) and inner surface (Fig. 2b) of the nanostructured Si layer, together with the corresponding remaining Si wafer surface after detachment of the layer (Fig. $2 \mathrm{c}$ ) reveal the typical morphology of the specimen. As shown in these figures, the bulk nanostructured $\mathrm{Si}$ layer exhibits different characterıstic morphologies on the two surfaces, both featuring a dense, triangular-like uniform macroarray which appears to be denser on the outer surface. The inner surface (Fig. 2b) exhibits a more uniform macroarray of regular triangular faceted large features of various sizes ranging from 0.5 to $1 \mu \mathrm{m}$ which contain secondary features of smaller dimensions $(<0.2 \mu \mathrm{m})$ which appear to be attached to the side walls, faces and corners of the primary macroarray. These two characteristic features produce a porous structure exhibiting primary pores of triangular cross section about $0.5-1 \mu \mathrm{m}$ and secondary (one order of magnitude smaller) pores propagating from the walls and corners of the main triangular pores (Fig. 2b). The SEM micrograph in figure 2c shows the typical morphology of the top side Si wafer remaining after detachment of the nanostructured Si layer called the macroporous Si layer [10]. Basically the morphology of this surface exhibits similar crystallographic effects, with dimensions of the triangular pores well correlated with those observed on the nanostructured Si layer at the inner surface. The characternstic faceted, triangular shaped pores illustrate an orientation dependence of the photo-anodization process of the (111) Si material, probably due to the known anisotropy of $\mathrm{Si}$ dissolution. We have observed this type of morphology with a series of PEC-etched, n-type (111) HD Si over a w1de range of etching current charges. 

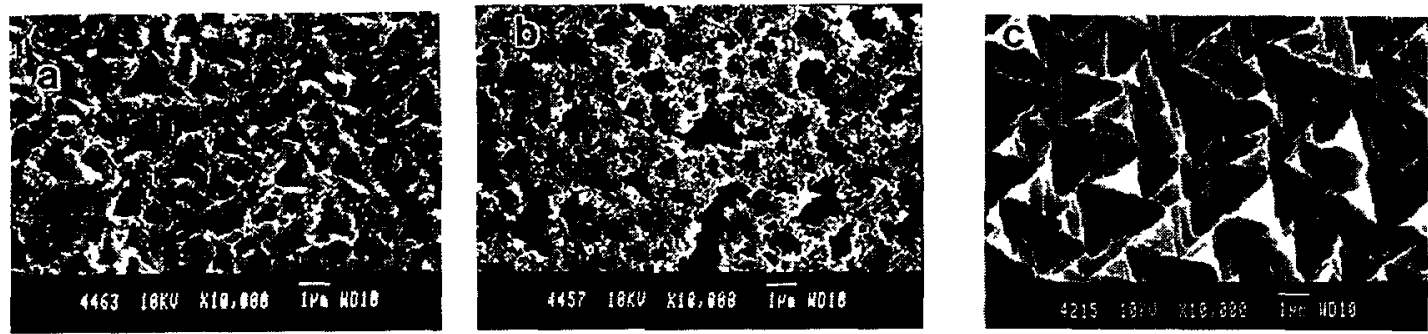

Fig. 2. - SEM micrographs (plan-view) of nanostructured Si layers on n-Si (111) highly doped, obtained by PEC-etching at $10 \mathrm{C} \mathrm{cm}^{-2}$ showing typical surface morphology of the top side surface (a) and interface surface (b); (c) shows the silicon wafer surface after detachment of the nanostructured Si layer.

TEM images in figure 3(a-e) reveal further microstructural and morphological details of the nanostructured silicon layer specimen studied by SEM in figures $2 \mathrm{a}$ and $2 \mathrm{~b}$. In the plan-view (see the low-mag TEM bright field (BF) image in Fig. 3a) the rigid triangular shaped macroarray network of $0.5-1 \mu \mathrm{m}$ sizes, apparently made of a bulky Si material and producing triangular macrovoids of $0.2 \mu \mathrm{m}$ up to $1 \mu \mathrm{m}$, is clearly seen. In some places this rigid triangular shaped macro-array network, which appeared to be a rigid bulk material, exhibits itself as a holey structure, displaying again triangular shaped voids with typical dimension one order of magnitude smaller. Bound to the rigid triangular shaped framework, contained within and completely fillıng-up the triangular voids, one can see nanostructured $\mathrm{Si}$, one order of magnitude smaller or less, featuring for instance long wires of uniform diameter at this scale.

The selected area transmission electron diffraction (SAD) pattern (Fig. 3b) recorded over the specimen area shown in figure $3 \mathrm{a}$ is well representative of the whole specimen. It exhibits a single crystal spot pattern characteristic of a perfect bulk Si material having, as expected, the original $\langle 111\rangle$ orientation of the Si wafer on which the PEC-etching has been performed. No diffuse ring, feature giving an indication of the presence of an amorphous phase, is visible. This SAD pattern shows weak (111) (220) and (311) rings together with the (220) and (422) spots.

Figure $3 \mathrm{c}$ shows a general view of the high resolution imaging performed on this specimen. Illustratıng the morphology and the dimensions of the individual crystallıne Si nanostructures existing within the triangular vords shown in figure 3a. The very thin wirelike structure observed in figure 3 a exhibits, at higher magnification, tangled Si wires of various diameter sizes of 3 to $20 \mathrm{~nm}$, which often undulate in width. Furthermore, these very thin filaments are not rigid and adopt various orientations probably due to internal stresses during the pore formation. As a matter of fact, most often (220) planes $(d=0.192 \mathrm{~nm})$ for the $\langle 111\rangle$ original zone axis and sometımes (111) planes $(d=0.313 \mathrm{~nm})$ for the $\langle 110\rangle$ zone axis, more clearly visible on such a medium magnification picture, are observed. The existence of a certain number of nanowires with different orientations may explain the weak rings observed on the SAD pattern (Fig. 3b). The (311) planes have an interreticular spacing of $0.165 \mathrm{~nm}$ which is too low to be imaged in the microscope.

Detaled structures of two single tangled wires are shown in figure $3 \mathrm{~d}$ ( $\langle 111\rangle$ orientation) and figure $3 \mathrm{e}(\langle 110\rangle$ orientation). Firstly, these HRTEM images confirm that the core of the wires consists of crystallized $S i$ of a few nm width. The microstructure shown in figure $3 \mathrm{~d}$ is typical of the general $\langle 111\rangle$ orientation of the specimen. The figure $3 \mathrm{e}$ shows a wire which has turned untıl reaching the $\langle 110\rangle$ orientation. Secondly, the crystallized core of the filament is clearly surrounded by a zone exhibiting typical granular contrast of a noncrystalline material. The thickness of this surrounding material is about 15 to $2 \mathrm{~nm}$. 
As a conclusion, such HRTEM images unambiguously demonstrate the existence of $\mathrm{Si}$ wires, with the required quantum-size range, consisting of a crystalline core embedded within an amorphous shell material.

3.3 LOCAL CHEMISTRY AND ELECTRONIC PROPERTIES. - Unfortunately the analysis of the shell material by HRTEM is not straightforward and spatrally-resolved EELS studies [23] have been performed in order to improve our knowledge of the local chemistry of these nanowires. It is now well established that one can investigate atomic bonding, and both filled and empty electronic states in inhomogeneous materials with a sub-nanometer spatial resolution from electron energy loss scatterıng data. Several examples concernıng silicon and Si-derived compounds have been published by Batson et al. [24], Ugarte et al. [25], Batson [26].
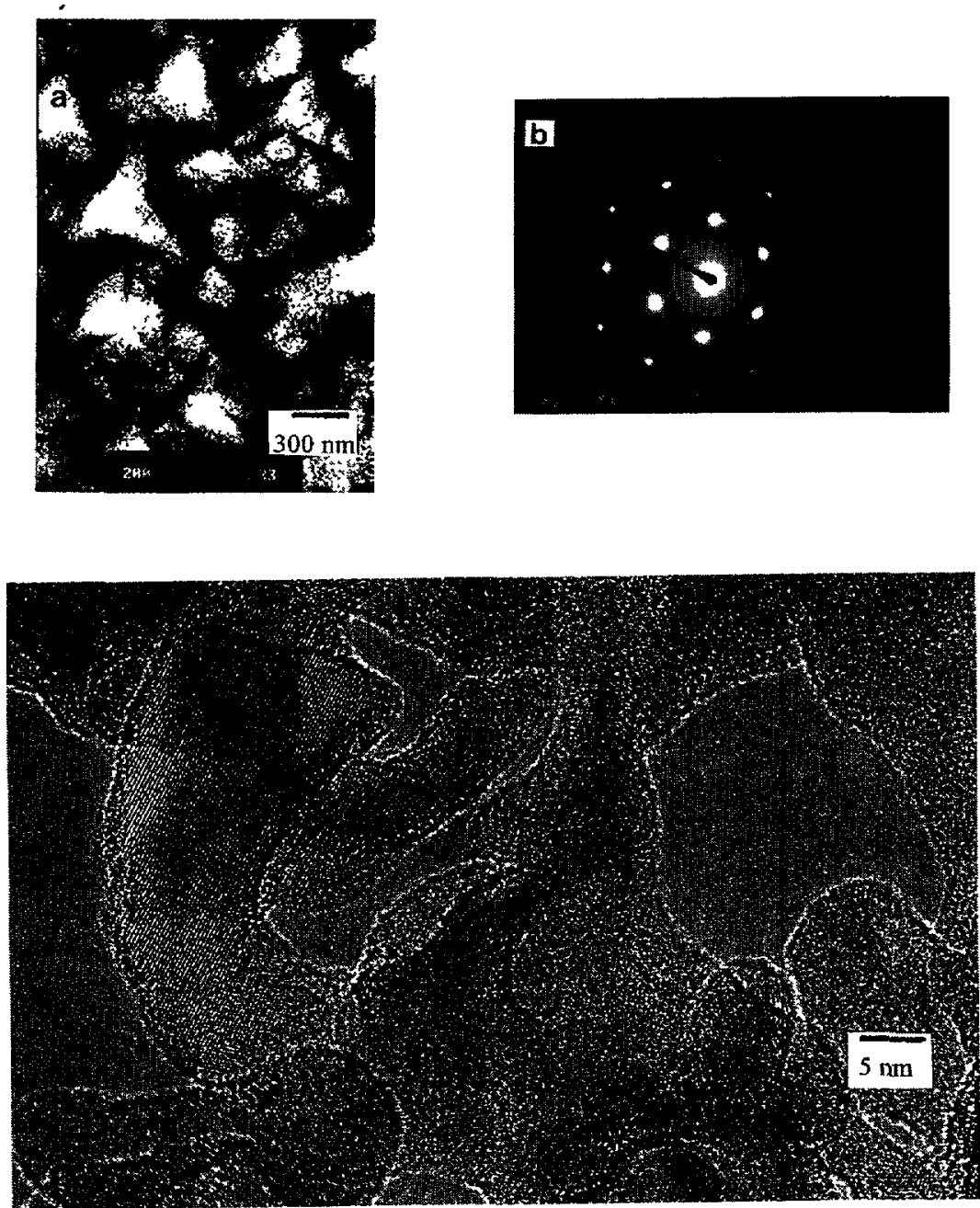

Fig. 3. - TEM micrographs of nanostructured Si layers on n-Si $\langle 111\rangle$ highly doped, obtained by PECetching at $10 \mathrm{C} \mathrm{cm}^{-2}$, (a) bright field plan-view image, (b) selected area diffraction pattern of the same area, (c) general view of a HRTEM imaging of the wires (at this relatively low magnification on the print the (220) planes are very faintly visible), (d) HRTEM image of a $\langle 111\rangle$ oriented filament, (e) HRTEM image of a $\langle 110\rangle$ oriented filament. 


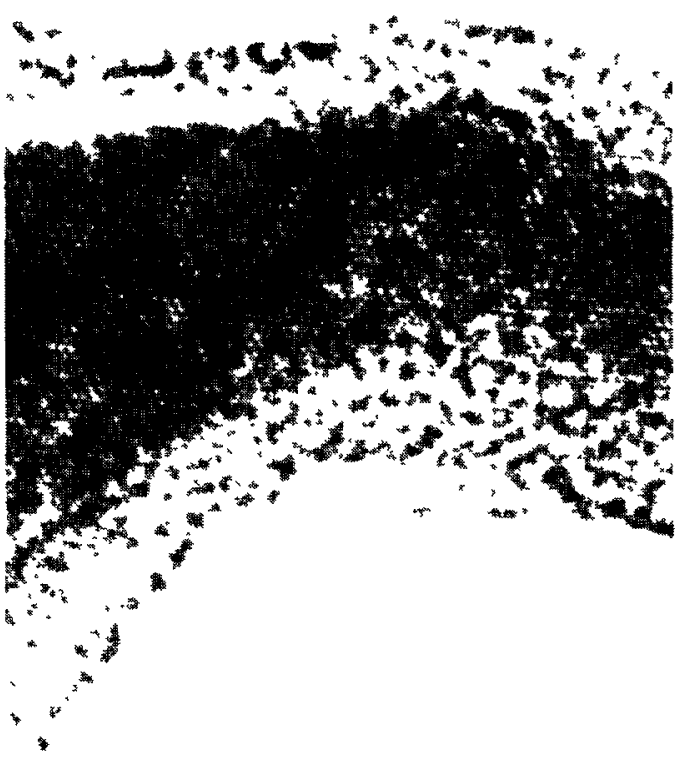

d)

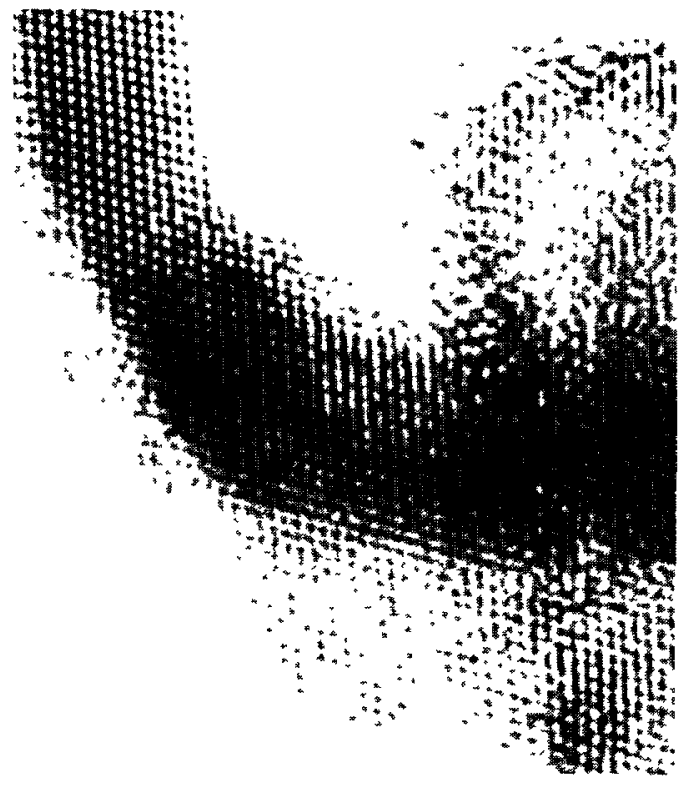

e)

Fig. 3 (continued).

The useful information arising from the electronic structure can be identified in the low energy loss region (from about 2 to $30 \mathrm{eV}$ ), as well as in the fine structures occuring on core 1onization edges, i.e. essentially the $\mathrm{Si} \mathrm{L}_{23}$ edge corresponding in the present case to the excitation of the silicon $2 p$ electrons to empty states. As a matter of fact, the precise location of the $\mathrm{Si} \mathrm{L}_{23}$ core ionization onset, its detailed shape within a few $\mathrm{eV}$ of the threshold, the intensity distribution over the first 10 to $30 \mathrm{eV}$ above edge usually called Energy Loss Near Edge Structure (ELNES), offer several keys to investigate charge transfer, empty conduction band states, local bonding symmetry and distance to nearest neighbours.

In the low energy-loss region, in the case of semiconductors and insulators, the observed spectral intensity distribution partially results from direct interband excitation. However, the local change in both the conduction and valence bands cannot easily be detected because this electron excitation domain is dominated by collective processes, bulk plasmons, interface plasmons, so that a very detailed analysis of the data is necessary to extract unambiguous facts.

As mentioned above, EELS spectra in this work have been recorded for these two energy loss ranges (0-30 eV over 1024 channels of $30 \mathrm{meV}$ width and $80-180 \mathrm{eV}$ over 1024 channels of $100 \mathrm{meV}$ width) using the line-spectrum mode. This technique unambiguously correlates the spectroscopic information to the subnanometer topography of the specimen. Therefore one acquisition consists of a set of spectra recorded at given positions, separated by a calibrated incremental distance of the order of $0.5 \mathrm{~nm}$, across a selected Si nanowire. Recording tımes are of the order of $50 \mathrm{~ms}$ per spectrum in the low loss range and a few $100 \mathrm{~ms}$ for the fine structures on the $\mathrm{Si} \mathrm{L}_{23}$ edge. It constitutes a satisfactory compromise between signal to noise considerations and stability of the probe with respect to the specimen. Let us recall that the spatial resolution itself is mostly governed, for such thin specimens, by the probe diameter, $1 \mathrm{e}$. also about $0.5 \mathrm{~nm}$ for the used illumination parameters. 
Data can then be displayed as a 3D intensity-plot along two axis, one corresponding to the energy loss scale and the other to the incident beam position. Figure 4a shows the detailed shape of the $\mathrm{Si}_{23}$ edge onset across an isolated nanowire, similar but slightly broader than the one shown in the high resolution electron micrograph. This perspective display of all $\mathrm{Si}$ $\mathrm{L}_{23}$ edges shows very similar shapes, positions and fine structures whatever is the probe position. In order to demonstrate it more clearly, single spectra can afterwards be selected from the above sequence. It has been done in figures $4 b$ and $4 c$ for a more refined study of the Si $L_{23}$ edge, near the outermost external surface of the wire, and in an intermediate domain close to the boundary between the crystalline core and the amorphous coverage respectively.

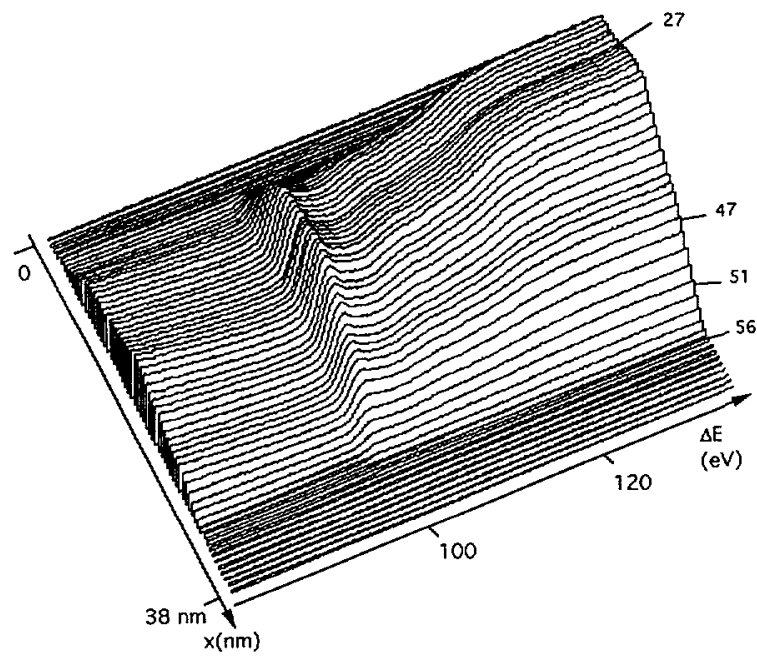

a)

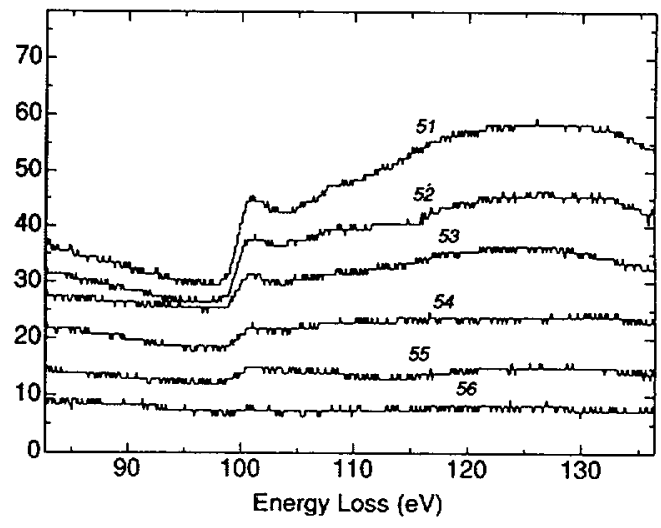

b)

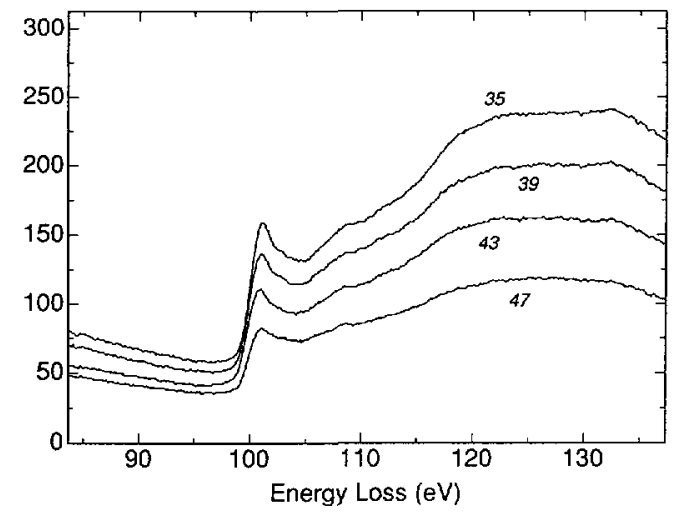

c)

Fig. 4. - (a) Sequence of EELS spectra acquired as the incident electron probe is scanned across a single Si wire. It displays the behaviour of the $\mathrm{Si}_{23}$ edge at $100 \mathrm{eV}$, explored with pixel increments of the order of $0.5 \mathrm{~nm}$. (b) Selection of spectra extracted from the above sequence (see numbers indexing the individual spectra), close to the outermost surface of amorphous material. (c) Selection of spectra extracted from the above sequence, at different positions within the wire. All vertical scales correspond to the number of counts in the relevant energy loss channel and pixel position. 
When approaching the specimen from the vacuum (spectrum 56 in Fig. 4b), the first spectrum exhibiting a distınguishable signal, that is recorded within about $0.5 \mathrm{~nm}$ of the surface (spectrum 55 in Fig. 4b) displays a clear edge at $100 \mathrm{eV}$ with a first maximum at about $101.5 \mathrm{eV}$. This behaviour remains constant across the whole wire (see spectra $\mathrm{n}^{\circ} 35,39,43$ and 47 at different positions within the wire). There is no detectable chemical shift, such as observed for Si atoms bound to different electronegative ligand atoms such as B, P, C, N and $\mathrm{O}$ [27]. In particular as demonstrated further on, the chemical shift for $\mathrm{SiO}_{2}$ is of the order of $6 \mathrm{eV}$.

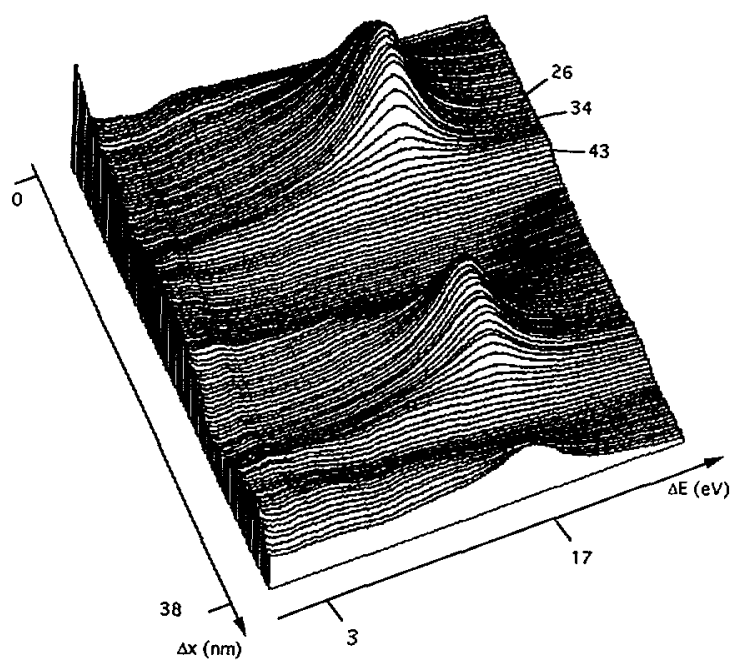

a)

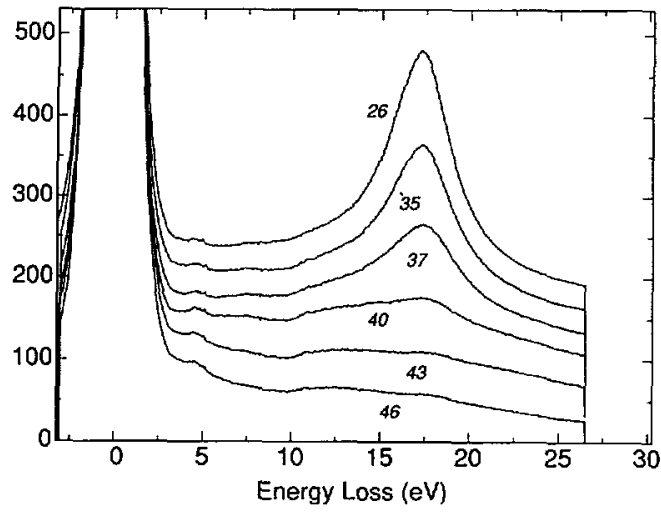

b)

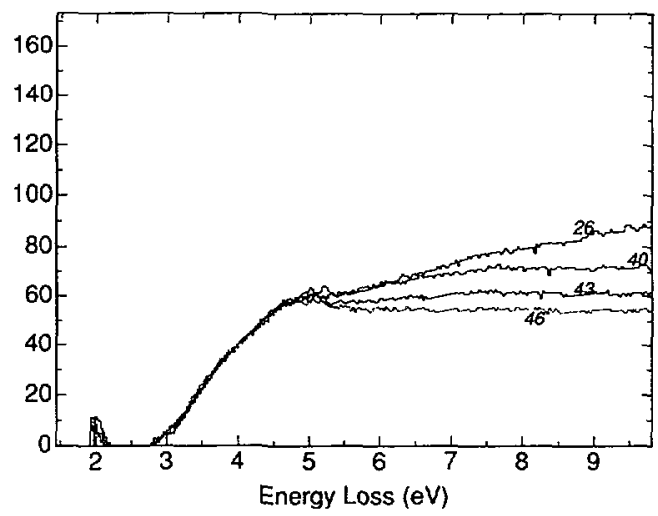

c)

Fig. 5. - (a) Sequence of EELS spectra in the 2-25 eV range, acquired as the incident probe is scanned across two adjacent Si wires. The energy loss scale has been truncated at about $1.5 \mathrm{eV}$ to get rid of the very high intensity of the zero loss peak. (b) Selection of spectra corresponding to the probe being scanned from the inner part of a wire towards the outside. The bulk Si plasmon peak is at $17 \mathrm{eV}$. (c) Detals of the absorption edge at about $3 \mathrm{eV}$, on the same spectra, after subtraction of the zero-loss decreasing intensity. The vertical intensity of the different spectra has been renormalized over the 3 to $5 \mathrm{eV}$ range in order to demonstrate the reproducibility of the structure, whatever is the exact probe position. 
Figure 5 shows data for the low loss region which are dominated first by the strong decrease of the zero-loss peak. Although its full width at half maximum is of the order of $0.5 \mathrm{eV}$, it extends to higher energies (for instance up to $2 \mathrm{eV}$ at $1 / 1000$ of the maximum intensity) and can therefore hinder the visibility of weak features in the $\mathrm{eV}$ energy loss domain. However one detects first an onset of transitions at about $2.8 \mathrm{eV}$ with two clearly identified bumps at 3.7 and $4.8 \mathrm{eV}$ followed by a continuum of transitions of variable intensity, then a weak edge at $10.5 \mathrm{eV}$ and finally the dominant Si volume plasmon peak loss at $17.0 \mathrm{eV}$. This latter peak is quite characteristic of the bulk crystallıne silicon spectrum. When moving the probe from the vacuum into nanoporous Si fibers, two major behaviours have been observed:

- the energy position of the volume plasmon does not shift noticeably, as long as it can be identified (see Fig. 5b) ;

- the two first structures at the onset of interband transitions are also quite identical across the whole structure (see Fig. 5c).

\section{Discussion.}

The factors which cause the formation and variations in the peculiar porous silicon morphology and which yield the luminescence are complex and diversified. Although they have been extensively investigated with many different spectroscopical tools, the physical origin of the luminescence has not yet been fully resolved.

A quantum confinement model $[1,13]$ has been proposed to explain light emission in the visible range. The presence of nano-sized crystallines wires would widen the gap compared to bulk silicon. Moreover the confinement of electron-hole pairs in real space would lead to a spread of wave functions in the reciprocal space so that radiative recombination would occur as a first order process. Support for this model has been provided by the optical absorption measurements performed on layers of different porosities. Theoretical calculations of the carrier confinement energy and of the radiatıve recombination time [2] seem to agree with experimental results.

Alternative models attribute the luminescence to the presence of different surfaces species such as $\mathrm{SiO}_{2}[18]$, siloxene-like compounds [14, 15] or amorphous silicon [19]. The central question is therefore to investigate whether the origin of luminescence is predominantly of bulk or surface nature. The tools used in the present study cannot answer directly this question. However as they have proved to be very effective to investigate on a very local scale the structural, electronic and chemical properties of the nanoporous silicon, they can help us, together with the support of other high resolution spectroscopies, to corroborate the role of the quantum sized crystalline Si.

4.1 EXISTENCE OF QUANTUM-SIZED CRYSTALline Si STRUCTURES. - The existence of quantum-sized crystalline Si structures is clearly demonstrated through the medium - and highresolution electron micrographs studies. Moreover, it is also shown that they are generally covered with a thin (typically $1 \mathrm{~nm}$ ) layer of amorphous material.

In a recent paper, Dumas et al. [28] have reported the nanometer-resolution mapping of visible light emission using a STM tip as a local source of electrons to excite cathodoluminescence. The simultaneous topographic and light intensity profiles reported by these authors reveal features with lateral dimensions on the scale of 1 to $5 \mathrm{~nm}$ that emit visible light in the 600 to $900 \mathrm{~nm}$ wavelength range. However, a clear relationship between these STM topographic structures and our TEM images cannot be established, as the STM tip used by 
these authors to probe the surface of the specimen is not well suited to explore such a 3D geometry with a complex distribution of wires and holes. The vertical scale in the STM image which exhibits height variations below $1 \mathrm{~nm}$ over a lateral surface of $40 \mathrm{~nm}$ demonstrates that the topographic information obtained by this technique is only very partial. As it investigates only the top surface of the porous layer, it does not constitute a clear evidence of the quantumsized nature of the specimen.

4.2 IDENTIFICATION OF THE NATURE OF THE AMORPHOUS COVERAGE. - i) To rule out the identification of the amorphous layer as a silica thin film, we have recorded under similar experımental conditions a line-spectrum sequence across a well identified $\mathrm{Si}_{-} \mathrm{SiO}_{2}$ test interface, oriented parallel to the incident electron beam.

Figure 6 shows the evolution of the $\mathrm{Si} \mathrm{L}_{23}$ edge which exhibits a quite clear and characteristic change from the $\mathrm{Si}$ to the $\mathrm{SiO}_{2}$ area. In the amorphous silica, it displays three peaks at 106.0, 108.5 and $115.5 \mathrm{eV}$ with no absorption over the $100-105 \mathrm{eV}$ range, which is in agreement with previous measurements on test specimens [29]. The first peaks have been interpreted as due to a Si-2p core exciton at $105.7 \mathrm{eV}$ followed by the $\mathrm{L}_{3}$ absorption edge at $107.1 \mathrm{eV} \mathrm{[30].} \mathrm{In} \mathrm{our} \mathrm{test} \mathrm{experiment,} \mathrm{we} \mathrm{notice} \mathrm{that} \mathrm{the} \mathrm{spectrum} \mathrm{recorded} \mathrm{within} 0.5 \mathrm{~nm}$ of the apex of the interface exhibits a residual jump at $100 \mathrm{eV}$ followed by the characteristic oxide lines $6 \mathrm{eV}$ higher in energy.

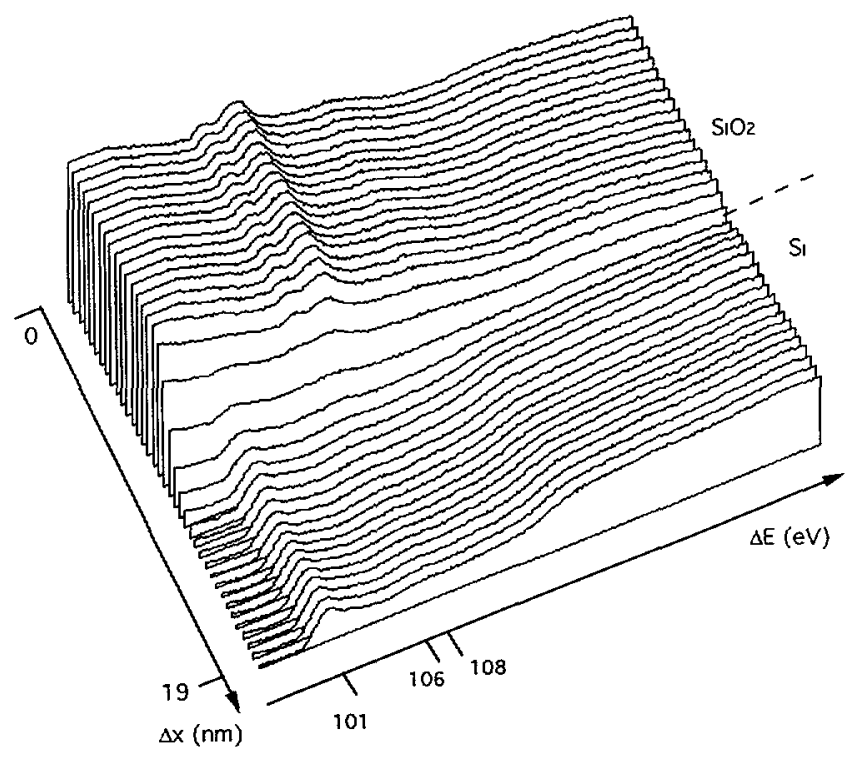

Fig. 6. - Test study of the variation of the $\mathrm{Si}_{23}$ edge when the probe is scanned across an interface $\mathrm{Si} / \mathrm{SiO}_{2}$, with experimental conditions similar to those used for the investigation of Si nanowires.

Another evidence for the absence of $\mathrm{SiO}_{2}$ coverage lies in the low-loss range. The reference line-spectrum across the $\mathrm{Si} / \mathrm{SiO}_{2}$ test interface is shown in figure 7. The plasmon line shifts from $16.9 \mathrm{eV}$ in $\mathrm{Si}$ to $23.5 \mathrm{eV}$ in $\mathrm{SiO}_{2}$ with an absorption edge at $9.7 \mathrm{eV}$. The first peak in this latter case is at $10.6 \mathrm{eV}$ and has been interpreted by Laughlin [31] as an excitonic resonance superimposed on a background of interband transitions. Several weak modulations occur at 14 , 16 and $20 \mathrm{eV}$ up to the bulk plasmon peak. On the interface itself, a boundary plasmon mode is visible at 6-7 eV and extends over 1-2 $\mathrm{nm}$ from the boundary. 


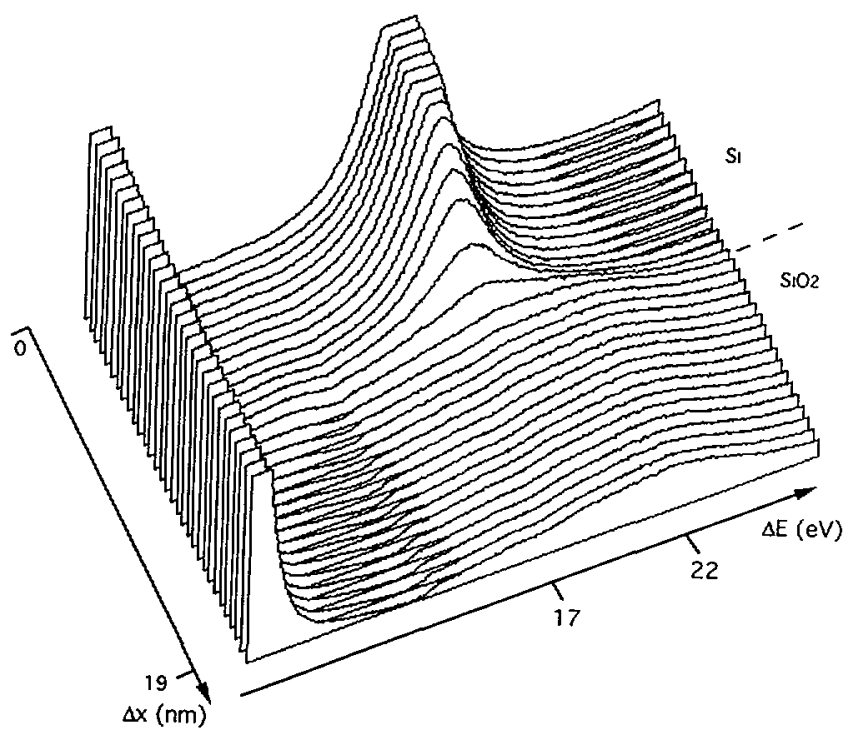

Fig. 7. - Same experiment as in figure 6, but concernıng the low-loss domain.

None of the features concerning the Si-2p energy loss range as well as the low-loss region on the $\mathrm{Si}-\mathrm{SiO}_{2}$ test interface, have been identified when moving the probe across the amorphous layer covering the Si nanocrystals. If weak features at $10.5 \mathrm{eV}$ and $106-108 \mathrm{eV}$ are visible across the whole fiber, they could be interpreted in terms of native oxide (due either to the growth process for the original bulk silicon single crystal or to the unavoidable presence of an oxygen surface contamination when handling the specimen in air before EM observation). However the weight of the Si-O bond which could be deduced from the relative intensity of these signals remains of the order of a few percent, when compared to the weight of the Si-Si bonds responsible for the edge shape at $100 \mathrm{eV}$.

11) Similarly in order to identify the chemical nature of the amorphous coverage, we have recorded the EELS fine structures on a reference sample of hydrogenated $\mathrm{Si}$. As the $\mathrm{Si}_{23}$ edge does not seem to differ significantly between the hydrogenated and the normal silicon spectra with a rounded edge at $100 \mathrm{eV}$, we have therefore considered more explicitly the lowloss spectra. Figures 8 and 9 summarıze the observed behaviours for crystallıne Si, amorphous $\mathrm{SiO}_{2}$, amorphous hydrogenated-Si and nanoporous $\mathrm{Si}$. The position of the plasmon peak exhibits weak shifts in opposite directions for the hydrogenated and nanoporous Si specimens with respect to the crystalline Si one. However the amplitude of the shifts is so weak that the reliability of this information can be questioned. The behaviour of the low-loss region close to the interband domain is more informatıve, because none of the investigated test specimens exhibits the same double peak absorption behaviour between 3.2 and $4.7 \mathrm{eV}$. This double peak constitutes a clear signature for the nanoporous Si specimens, as it reveals a strong interband excitation process in this energy domain just above the visible range.

111) Higher energy resolution spectroscopies on the $\mathrm{Si}-2 \mathrm{p}$ have been recently used to investigate the conduction band structure in nanoporous Si. X-ray absorption measurements have been performed with a sub-0.1 eV resolution on native, oxidized and refreshed porous ptype Si specimens [32]. They have exhibited a blueshift of the order of $0.3 \mathrm{eV}$ on the porous specımen and a loss of fine structure. In the absence of spatial resolution which would discriminate the contribution of specimen features with different characteristic dimensions, 


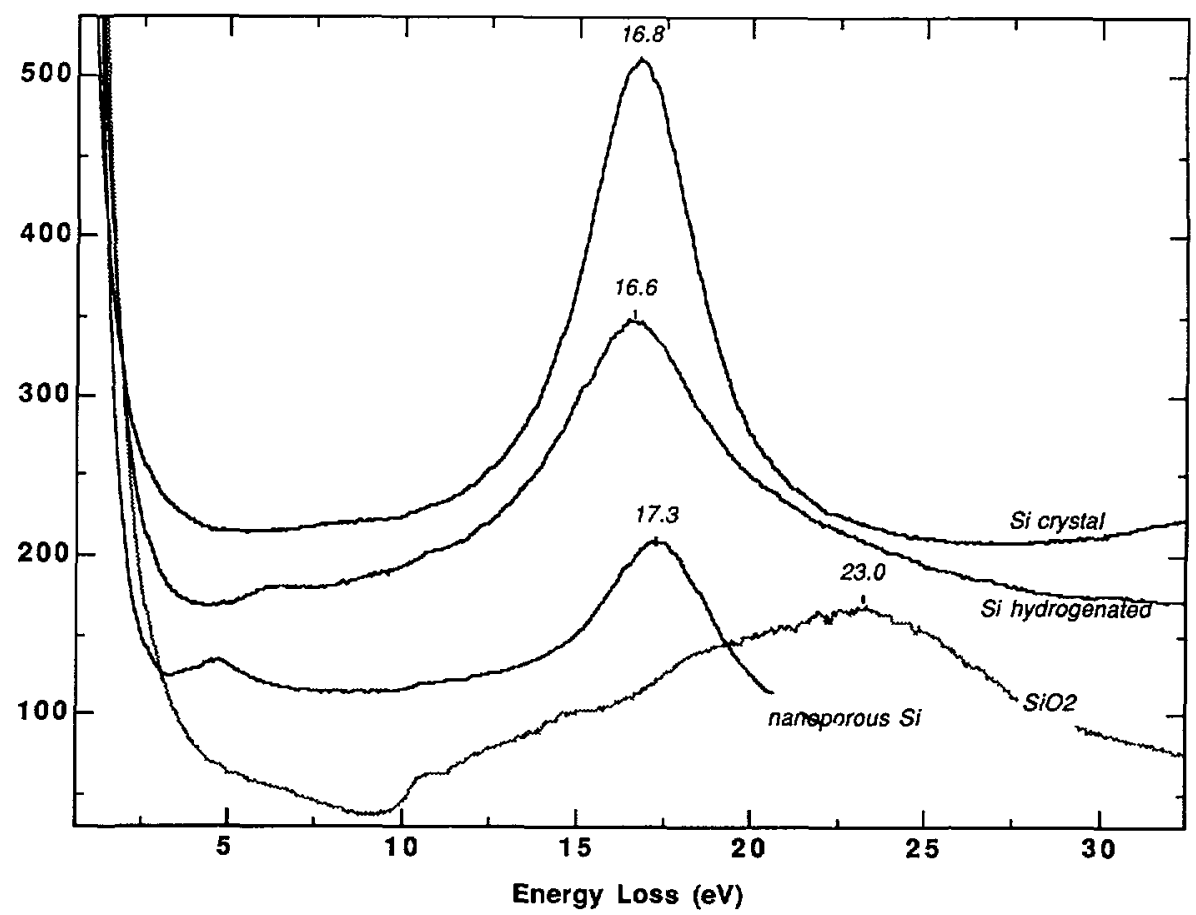

Fig. 8. - Comparison of the low-loss spectra (and in particular of the plasmon peaks) in different reference specimens with that recorded on the center of a nanoporous $\mathrm{Si}$ wire.

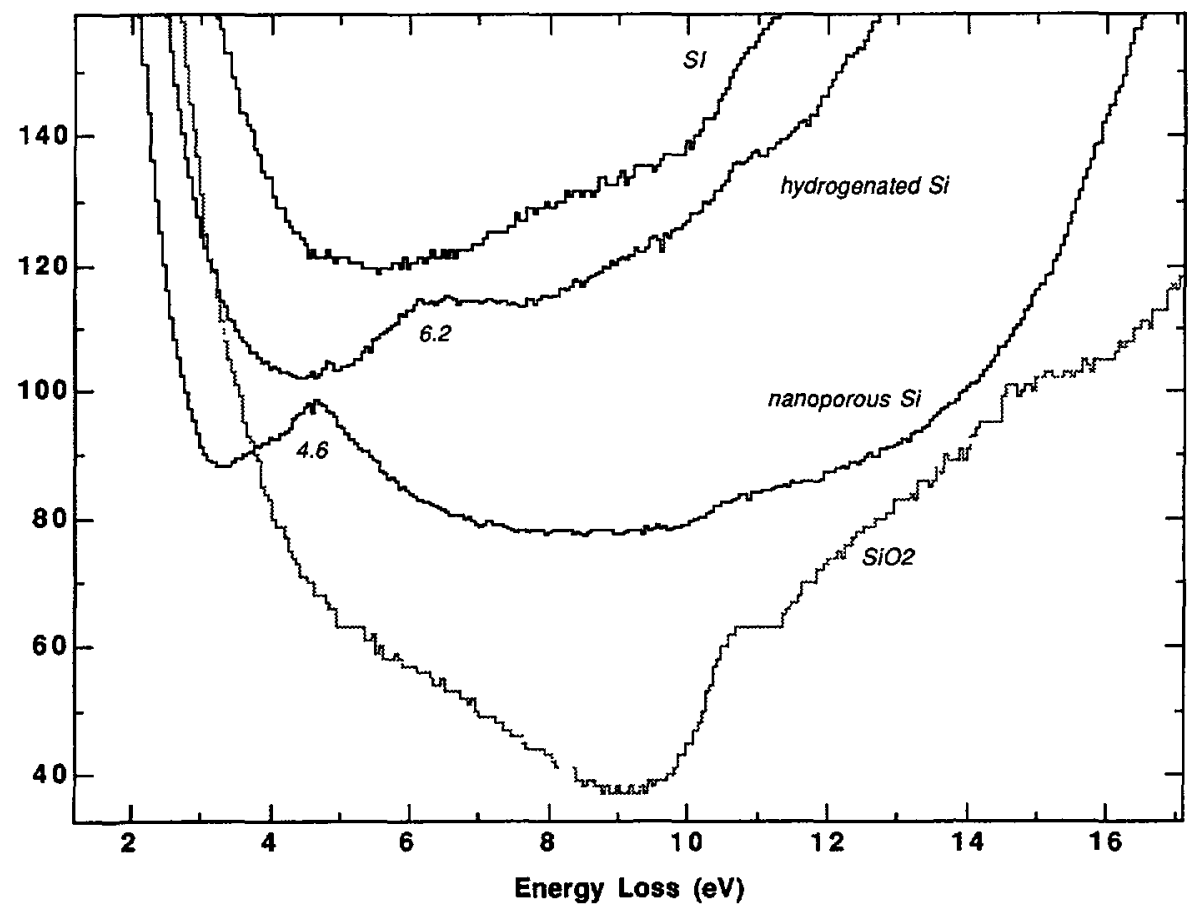

Fig. 9. - Same spectra as above but with emphasis on the onset of interband transitions in the 3 to $10 \mathrm{eV}$ energy loss range. 
these measurements, showing that the energy of the bottom of the silicon conduction band would be raised in average by $0.29 \mathrm{eV}$, can be interpreted in accordance with a quantum confinement description. The loss of resolution can be described as a convolution by a Gaussian broadenıng function of $0.45 \mathrm{eV}$ FWHM to simulate the distribution of quantum shifts over a range of length scales.

Although it concerns a different kind of lumınescent Si specimens, the study performed by Batson and Heath [33] is of great interest. It relates the fine structures observed on the EELS $\mathrm{L}_{23}$ edge (performed with a $0.25 \mathrm{eV}$ energy resolution on the special IBM instrument) to the size and shape of single H-terminated Si nanocrystals. They show that for sizes below $5 \mathrm{~nm}$, the conduction band edge shape exhibits a single band edge profile, shifts to higher energies as the inverse square of the particle radius and displays a large increase in oscillator strength. This behaviour slightly deviates from that observed in X-ray absorption spectroscopy on porous $\mathrm{Si}$ (see Van Buuren et al. [32]) in which case the edge shift is observed without a change in its overall shape. These discrepancies seem to result from a relaxation of the dipole selection rules in the EELS, although the authors admit that they have not yet a detailed understanding of the shape of the enhancement at the edge.

Finally, useful complementary arguments concerning the origin of the luminescence can be found in the synchrotron-light-induced optical luminescence on porous Si performed by Sham et al. [34]. They compare the total electron yield with photoluminescence yreld measurements on the silicon $\mathrm{K}$ edge at $1845 \mathrm{eV}$. As they can discriminate the $\mathrm{X}$-ray absorption fine structure of the Si sites that produce luminescence from those that do not, they demonstrate that porous slicon is essentially crystalline silicon locally, that the surface silicon oxide constituents are not responsible for the photoluminescence and that the luminescence is not of the same origin as in pure siloxene, HF-treated siloxene or thermally annealed siloxene.

iv) Considering the role of the amorphous silicon in the luminescence process which has been suggested by Vasquez et al. [19] from XPS studies, it seems definitly possible to rule it out for several reasons. These authors claim that their « valence-band spectra provide unambiguous evidence that the light emitting porous $\mathrm{Si}$ samples consist of a-Si at least in the top few tens of angströms from which XPS data originate, which notably is the same length scale as the absorption depth in non-porous a-Si of the $365 \mathrm{~nm}$ light which excites the luminescence ». First, as it is stated, this assertion does not contradict our own HRTEM observations which demonstrate the rather general presence of a typically $1 \mathrm{~nm}$ thick amorphous $\mathrm{Si}$ layer on the crystalline $\mathrm{Si}$ surface in nanoporous $\mathrm{Si}$.

On the other hand, two experimental observations quoted in the previous discussion seem to deny the origin of luminescence to the presence of a-Si. The first one is the blue-shift on the Si $\mathrm{L}_{23}$ absorption edge, which has not been observed on amorphous silicon relative to crystalline silicon (see discussion in Van Buuren et al. [32]). The second one is the spatially dependent photon signal in the STM experiments by Dumas [28]. If it had to be associated with the presence of a-Si, our TEM observations would predict a rather homogeneous photon intensity distributed over the whole surface.

In conclusion, our own HRTEM and EELS results carrying a spatially localized information on the specimen, support, together with the high energy resolution spectroscopic measurements which average the information over wide areas, the interpretation of the luminescence in nanoporous $\mathrm{Si}$ in terms of quantum-confinement models. Within the detection limits of the techniques employed, we cannot eliminate completely the existence of an oxygen or hydrogen content equivalent to approximately one monolayer lying either on the interface between the crystal and the amorphous skin, or on the outside surface. 


\section{Acknowledgements.}

We would like to thank $C$. Vard for his technical assistance with the SEM measurements. This work was supported in part by a CEE Contract (HCM-CHRX-CT92-0059) and the PIRSEMCNRS through a Concerted Research Action on multicrystalline silicon. A.A.Y. is grateful to the French Foreign Office Ministry for the support of her stay in the CNRS laboratory.

\section{References}

[1] Canham L. T., Appl. Phys. Lett. 57 (1990) 1046.

[2] Materials Research Society Proceedings, vol. 256 «Light Emission from Silicon», S. S. Iyer, R. T. Collins and L. T. Canham Eds. (Pittsburg, PA, 1993).

[3] Halimaouı A., Oules C., Bomchil G., Bsiesy A., Gaspard F., Herino R., Ligeon M. and Muller F., Appl Phys. Lett. 59 (1991) 304.

[4] Jung K. H., Sih S. and Kwong D. L., J. Electrochem. Soc. 140 (1993) 3046.

[5] Smith R. L. and Collins S. D., J. Appl. Phys. 71 (1992) RI-R22 and references therein.

[6] Searson P. C., Macaulay J. M. and Prokes S. M., J. Electrochem Soc. 139 (1992) 3373 and references therein.

[7] Lévy-Clément C., Lagoubi A., Tenne R. and Neumann-Spaltart M., Electrochemica Acta 37 (1992) 877 and reference herein.

[8] Lévy-Clément C., Lagoubi A., Ballutaud D., Ozanam F., Chazalvıel J. N. and Neumann-Spallart M., Appl. Surf. Scl 65/66 (1993) 408.

[9] Albu-Yaron A., Bastide S., Maurıce J. L. and Lévy-Clếment C., Light emissıon from sılıcon, J. C. Vial, L. T. Canham and W. Lang Eds., J. Luminescence 57 (1993) 67.

[10] Lévy-Clément C., Lagoubi A. and Tomkiewicz M., J. Electrochem. Soc. 141 (1994) 958.

[11] Lagoubi A., Neumann-Spallart M., Bastıde S., Lévy-Clément C., Proc. 11 th European Photovoltaic Solar Energy Conference, Montreux, october 1992 (Harwood Academic Publishers, 1993) pp. 250-253.

[12] Galun U., Lagoubi A., Tenne R. and Lévy-Clément C.. Light emıssion from silıcon, J. C.Vial, L. T. Canham and W. Lang Eds., J. Luminescence 57 (1993) 125.

[13] Lehmann V. and Gosele U., Appl. Phys. Lett. 58 (1991) 856.

[14] Brandt M. S., Fuchs H. D., Stutzmann M., Weber J. and Cardonna M., Solıd State Commun. 81 (1992) 307.

[15] Deak P., Rosenbauer M., Studzmann M., Weber J. and Brandt M. S., Phys. Rer. Lett. 69 (1992) 2531.

[16] Tsal C., Li K. H., Sarathy J., Shih S., Campbell J. C., Hance B. K. and White J. M., Appl. Phys. Lett. 59 (1991) 2814.

[17] Prokes S. M., Glembocki O. J., Bermudez V. M., Kaplan R., Friedsdorf L. E. and Searson P. C., Phys. Rev. B 45 (1992) 13788.

[18] Pickering C., Beale M. I. J., Robbins D. J., Pearson P. J. and Greef R., J. Phys. C 17 (1984) 6535.

[19] Vasquez R. P.. Fathauer R. W.. George T., Ksendzov A. and Lin L. T., Appl. Phys. Lett. 60 (1992) 1004.

[20] Albu-Yaron A., Frank A., Hodes G. and Noufi R., Thin Solid Films 227 (1993) 18.

[21] Collıx C., Tencé M., Lefèvre E., Mory C., Gu H., Bouchet D., Jeanguıllaume C., to be published in Mikrochenical Acta, Proc. 3rd Conference of the European Microbeam Analysis Society, Rimını (1993).

[22] Mory C., Tencé M., Colliex C., J. Microsc. Spectrosc. Electron 10 (1985) 381.

[23] Colliex C., Transmission Electron Energy Loss Spectrometry in Materials Science, M. M. Disko, C. C. Ahn, B. Fultz Eds. (The Minerals, Metals and Materials Society, 1992) p. 85.

[24] Batson P. E., Kavanagh K. L., Wong C. Y., Wood J. M., Ultrameroscopy 22 (1987) 89.

[25] Ugarte D., Collex C., Trebbia P., Phys. Rev. B 45 (1992) 4332. 
[26] Batson P. E., Ultramicroscopy 50 (1993) 1.

[27] Auchterlonie G. J., Mac Kenzie D. R., Cockayne D. J., Ultramecroscopy 31 (1989) 217.

[28] Dumas P., Gu M., Syrykh C., Gimzewski J. K., Makarenko F., Halimaoui A. and Salvan F., Europhys. Lett. 23 (1993) 197.

[29] Dorı L., Bruley J., Di Marıa D. J., Batson P. E., Tornello J., Arienzo M., I. Appl. Phys. 69 (1991) 2317.

[30] Jeyasingh Nithianandam V. and Schnatterly S. E., Phys. Rev. B 38 (1988) 5547.

[31] Laughlin R. B., Phys. Rev. B 22 (1980) 3021.

[32] Van Buuren T., Gao Y., Tiedje T., Dahn J. R., Way B. M., Appl. Phys. Lett. 60 (1992) 3013.

[33] Batson P. E., Heath J. R., Phys. Rev. Lett. 71 (1993) 911.

[34] Sham T. K., Jiang D. J., Coulthard I., Lorimer J. W., Feng X. H., Tan K. H., Frigo S. P., Rosenberg R. A., Houghton D. C., Bryskiewicz B., Nature 363 (1993) 331. 